\title{
HEALTH HAZARDS, OCCUPATIONAL SAFETY MEASURES AND KNOWLEDGE ASSESSMENT AMONG NURSES EXPOSED TO CHEMOTHERAPY DRUGS IN AIN SHAMS UNIVERSITY HOSPITALS, EGYPT
}

\author{
By \\ El Hosseini DM, Ghanem EA and Gamal DA \\ Department of Occupational and Environmental Medicine, Faculty of Medicine, Ain Shams University. \\ Corresponding author: El Hosseini DM: doaa.elhussiney@med.asu.edu.eg
}

\begin{abstract}
Introduction: Several chemotherapeutic drugs are known to be teratogenic and mutagenic to humans. Nurses are the main group of health care workers that are exposed to these drugs during their work. Generally, the work activities that pose the greatest risk of exposure are the preparation and administration of antineoplastic drugs, and cleaning of chemotherapy spills. Aim of work: 1) To estimate the prevalence of hazardous effects to which nurses handling cytotoxic drugs (CDs) are exposed 2) To evaluate the current safety measures used in clinical practice and 3) To assess nurses' knowledge regarding cytotoxic Drugs. Materials and methods: A cross-sectional study was carried out at the Oncology and Hematology unit at Ain Shams University Hospitals, Egypt. The study was carried out on (73) nurses. A convenience sampling was used to select the study subjects using well-structured self-administered questionnaire and observational check list. Collected data were analyzed using descriptive and inferential statistics. Result: Almost more than half of the study nurses frequently complained from recurrent headache (64.4\%), skin irritation (63\%), eye irritation (61.6\%), and hair loss $(52.1 \%)$. Reproductive effects were also found: menstrual irregularities (32.9\%), low birth weight babies (23.3\%), premature labor (19.2\%), and malignancy (15.1\%). During handling CDs, the majority of nurses $(89 \%)$ utilized gloves, (61.6\%) utilized gowns, and none of them utilized goggles. About (72. \%) had fair total knowledge score regarding CDs, and only few of them (11.0\%) had good total score. Conclusion: Toxic effects of CDs were highly prevalent among the studied nurses. The safety practice and adopting protective measures among the majority were not consistent with the National Institute for Occupational Safety and Health (NIOSH) guidelines despite the fair total knowledge score they had.
\end{abstract}

Keywords: Nurses, Chemotherapy, Health hazards, Occupational safety measures and Knowledge. 


\section{Introduction}

Antineoplastic drugs are used extensively in health care to treat cancer patients and are increasingly being used to treat arthritis, multiple sclerosis, and other non-cancer medical conditions (NIOSH, 2013). Most antineoplastic drugs are hazardous. According to the World Health Organization, more than 11 million patients worldwide are diagnosed as cases of cancer. This number is expected to rise to 16 million by 2020 (WHO, 2006). Chemotherapy is still the main treatment regimen for cancer, and approximately 50\% of patients with cancer receive chemotherapy (Connor and Mcdiarmid, 2006). The widespread use of (CDs) has raised concern about the risks to health care workers who use them. Occupational exposure mainly occurs during preparation and administration of these drugs. Nurses are the main group that is exposed to these drugs in the patient-care settings (krstev et al., 2003). They handle several CDs in their most concentrated form over prolonged periods of time. In addition, oncology nurse's main function is to administer CDs to the patients, and in some instances drugs may also be prepared by her particularly in the absence of clinical pharmacy unit (Elshamy et al., 2010).

Although the potential therapeutic benefits of hazardous drugs outweigh the risks of their side effects for ill patients, exposed health care workers risk the same side effects with no therapeutic benefit. Acute health effects associated with occupational exposure include skin rashes, sore throat, headache, eye irritation, hair loss, as well as adverse reproductive outcomes including infertility, spontaneous abortion and congenital malformation (NIOSH, 2004).

Several studies investigated the health risks associated with exposure to CDs drugs among nurses. An interesting Egyptian study found a high level of genotoxicity biomarkers including chromosomal aberrations among oncology nurses (Anwar et al., 1994). Another study found that $31.4 \%$ of oncology nurses had abortion vs. $10.3 \%$ of a control group, while infertility was $14.3 \%$ vs. $3.4 \%$, respectively (Elshamy et al., 2010).

Organizations such as the National Institute for Occupational Safety and Health (NIOSH), and the Occupational Safety and Health Administration (OSHA) have developed guidelines to 
protect health care workers from adverse effects of occupational exposure to CDs. The recommended methods for reducing hazardous drugs exposure include :1) biological safety cabinets (BSCs) to protect against inhalation exposure during drug preparation; 2) two pairs of disposable gloves that are powder proof; 3) a disposable gown with long sleeves, cuffs and back closure; 4) a respirator to protect against aerosols; 5) eye and face shield that provides splash protection. All precautions, when used consistently, can reduce occupational exposure to hazardous drugs (NIOSH, 2004 and OSHA, 2016).

Health care workers who handle CDs drugs must be aware of the existing hazards and safe handling practices of cytotoxic drugs because this has been associated with improvement of safety of both patients and health care workers (Al-Azzam et al., 2015).

In Egypt, the burden of the disease is high; there is a dearth of nurses especially oncology certified nurses, while there is an increase in patient volume. This makes nurses overwhelmed and frustrated. Previous Egyptian studies show weak compliance of nurses' practice with safe-handling guidelines (Elshamy et al., 2010 and
Mohamed, 2015). There is scarcity of Egyptian researches in this area, thus the current study was conducted to evaluate the existing system of safe handling and the health risks associated with the exposure to cytotoxic drugs among nurses involved in this study.

\section{Aim of work}

1) To estimate the prevalence of hazardous effects to which nurses handling cytotoxic drugs (CDs) are exposed 2) To evaluate the current safety measures used in clinical practice and 3) To assess nurses' knowledge regarding cytotoxic Drugs.

\section{Materials and methods}

Study design: It is an analytical cross sectional study.

Place and duration of the study: The study was conducted at the Oncology unit, adult and pediatric Hematology unit in Ain Shams University Hospitals; during the period from October 2017 to March 2018.

Study sample: A convenience sample consisted of 73 nurses who handled Cytotoxic Drugs (CDs) for at least 6 months was chosen. The nurses were recruited from the Oncology unit (56), Adult Hematology unit (7), and Pediatric Hematology unit (10) at Ain 
Shams University hospitals. Exclusion criteria were: workers exposed to CDs for less than 6 months as well as those with known uncontrolled chronic medical conditions; (cardiac problems, diabetes, respiratory diseases, bleeding disorders and any past cancer diagnosis before handling CDs). The aim of this stringent selection in terms of health status and duration of work was to avoid any unrelated symptoms reporting by the nursing staff during the study.

\section{Study methods:}

\section{Two self-administered question-} naires and an observational check list were utilized for data collection. These questionnaires were developed by the researchers in Arabic language based on the review of related literatures.

\section{A-The first questionnaire aimed} to collect data on the following points:

1-Socio-demographicand job characteristics such as; age, level of education, marital status, work department and number of years handling CDs

2- Adverse effects during work due to exposure to CDs: acute effects such as: headache, skin rash, running nose, metallic taste, vomiting and hair loss and chronic effects such as: menstrualirregularities, spontaneous abortion, congenital anomalies, infertility, learning disabilities in children and malignancy.

3-Safety measures applied by nurses as recommended by the National Institute for Occupational safety and Health (NIOSH) such as: utilization of personal protective equipment in the workplace when handling $\mathrm{CDS}$, washing hand after removing gloves, protective measures used during spills.

4- Barriers to compliance with the NIOSH guidelines such as: work overload, lack of supervision, lack of knowledge, and shortage of personal protective devices (PPDs) (NIOSH, 2007).

5- Risky behaviors and accident occurrence such as: eating, drinking, priming IV tube at patient bed, taking contaminated clothes home; and spills or leak of antineoplastic drugs during administration.

6- Oncology unit assessment by nurses such as: availability of PPDs, work overload, head nurse supervision, availability of clear policies, restriction of pregnant workers from handling CDs, medical surveillance program for employees, and availability of laminar air flow hood in the unit. 
B-The second questionnaire aimed to; evaluate the level of knowledge of the participants regarding $\mathrm{CDs}$, on the way of exposure to CDs and the safety handling procedures. The form was developed according to the principles and standards of OSHA directives (OSHA, 2011). It included 36 true and false questions to assess nurses' knowledge regarding the following: cytotoxic anticancer drugs and their hazardous effects (8 questions), methods of exposure to cytotoxic drugs (8 questions) and safe handling measures (20 questions). The correct answer was given (1 grade), the incorrect answer was given (zero), and scores were summed up with the higher score indicating good knowledge as follows:

- A total score of zero to 17 indicated poor total score.

- A total score of 18 to 27 indicated fair total score.

- A total score of 28 to 36 indicated good total score.

Nurses were also asked about training courses, sources of information and their desire to have more education.

\section{C- Observational check list:}

It was developed by the researchers to assess nurses' actual practice of handling and administration of cytotoxic drugs. It consisted of statements, to be checked by the researchers, on whether they are carried out by the nurses or not such as: the use of personal protective equipment during handling of CDs or during spills, immediate change of any contaminated personal protective equipment, and washing hands thoroughly after any contact with cytotoxic drugs.

All the tools were developed by the researchers after extensive review of literature. A pilot study was conducted prior to data collection on five participants to test clarity and applicability of the questionnaires, and necessary modifications were done in some questions.

\section{Consent}

Respondents' verbal consent to participate in the study was obtained after explanation of the aim of the study and reassuring them that all the received data will be confidential.

\section{Ethical approval}

Approval of the Ethical Committee of the Faculty of Medicine, Ain Shams University was obtained prior to starting the study. 


\section{Data management}

The collected data were analyzed using the statistical package for social science (SPSS) version 18. Quantitative data were presented as mean and standard deviation (Mean $\pm \mathrm{SD}$ ); qualitative data were presented as percentage $(\%)$. For analysis, Fisher exact test was used. The significance of the observed difference was obtained at $\mathrm{p}<0.05$.

\section{Results}

This cross-sectional study included 73 nurses who used to handle cytotoxic drugs for more than 6 months. The mean age of participants was $34.2 \pm 7.09$ years and the mean years of work experience was $10.33 \pm 7.13$. More than three quarters of them were married (78.1\%). Regarding education, the majority of the study nurses had Diploma of Nursing (82.2\%), while only (17.8\%) had Baccalaureate degree .The majority $(76.8 \%)$ of the nurses worked in the Oncology unit, and more than half of them (67.1. \%) handled anticancer drugs more than 4 days per week. While (20.5\%) handled two to three days per week and only $(12.4 \%)$ handled CDs once per week. The nurses were asked about the places where the CDs were prepared, $(42.5 \%)$ reported that anticancer drugs were prepared in the pharmacy, while (27.4\%) of cases said that they were prepared in the unit and (30.1\%) reported both. Evaluation of risky clinical activities during the daily routine work revealed that spills or leakage of CDs during administration was the most frequent risky behavior (57.5\%), followed by priming IV tube at patient bed (53.5\%) and taking contaminated clothes home (49.3\%) . Eating in the preparation room, drinking and storing food and beverages were reported by $(25.7 \%),(30.4 \%),(18.6 \%)$ of nurses, respectively (Data were not tabulated).

\section{Table (1): Toxic effects of CDs among respondents (No=73)}

\begin{tabular}{|l|c|c|}
\hline Toxic effects of CDs & $\mathbf{N o}=\mathbf{7 3}$ & $\%$ \\
\hline Acute toxic effects & & \\
\hline Headache & 47 & \\
Yes & 26 & $64.4 \%$ \\
NO & & $35.6 \%$ \\
\hline Skin irritation & 46 & $63 \%$ \\
Yes & 27 & $37 \%$ \\
NO & & \\
\hline
\end{tabular}




\begin{tabular}{|c|c|c|}
\hline $\begin{array}{l}\text { Eye irritation } \\
\text { Yes } \\
\text { NO }\end{array}$ & $\begin{array}{l}45 \\
28\end{array}$ & $\begin{array}{l}61.6 \% \\
38.4 \%\end{array}$ \\
\hline $\begin{array}{l}\text { Upper airway irritation } \\
\text { Yes } \\
\text { NO }\end{array}$ & $\begin{array}{l}37 \\
36\end{array}$ & $\begin{array}{l}50.7 \% \\
49.3 \%\end{array}$ \\
\hline $\begin{array}{l}\text { Metallic taste } \\
\text { Yes } \\
\text { NO }\end{array}$ & $\begin{array}{l}24 \\
49\end{array}$ & $\begin{array}{l}32.9 \% \\
67.1 \%\end{array}$ \\
\hline $\begin{array}{l}\text { Nausea or vomiting } \\
\text { Yes } \\
\text { NO }\end{array}$ & $\begin{array}{l}30 \\
43\end{array}$ & $\begin{array}{l}41.1 \% \\
58.9 \%\end{array}$ \\
\hline $\begin{array}{l}\text { Hair loss } \\
\text { Yes } \\
\text { NO }\end{array}$ & $\begin{array}{l}38 \\
35\end{array}$ & $\begin{array}{l}52.1 \% \\
47.9 \%\end{array}$ \\
\hline $\begin{array}{l}\text { Symptoms improved on vacation } \\
\text { Yes } \\
\text { NO }\end{array}$ & $\begin{array}{l}43 \\
18\end{array}$ & $\begin{array}{l}70.5 \% \\
29.5 \%\end{array}$ \\
\hline Chronic toxic effects of CDs & $\mathrm{No}=73$ & $\%$ \\
\hline $\begin{array}{l}\text { Menstrual irregularities } \\
\text { Yes } \\
\text { NO }\end{array}$ & $\begin{array}{l}24 \\
49\end{array}$ & $\begin{array}{l}32.9 \% \\
67.1 \%\end{array}$ \\
\hline $\begin{array}{l}\text { Spontaneous abortion } \\
\text { Yes } \\
\text { NO }\end{array}$ & $\begin{array}{l}13 \\
60\end{array}$ & $\begin{array}{l}17.8 \% \\
82.2 \%\end{array}$ \\
\hline $\begin{array}{l}\text { Congenital anomalies } \\
\text { Yes } \\
\text { NO }\end{array}$ & $\begin{array}{c}7 \\
66 \\
\end{array}$ & $\begin{array}{c}9.6 \% \\
90.4 \%\end{array}$ \\
\hline $\begin{array}{l}\text { Infertility or sub fertility } \\
\text { Yes } \\
\text { NO }\end{array}$ & $\begin{array}{l}13 \\
60 \\
\end{array}$ & $\begin{array}{l}17.8 \% \\
82.2 \% \\
\end{array}$ \\
\hline $\begin{array}{l}\text { Premature labor } \\
\text { Yes } \\
\text { NO }\end{array}$ & $\begin{array}{l}14 \\
59 \\
\end{array}$ & $\begin{array}{l}19.2 \% \\
80.8 \% \\
\end{array}$ \\
\hline $\begin{array}{l}\text { Low birth weight babies } \\
\text { Yes } \\
\text { NO }\end{array}$ & $\begin{array}{l}17 \\
56 \\
\end{array}$ & $\begin{array}{l}23.3 \% \\
76.7 \% \\
\end{array}$ \\
\hline $\begin{array}{l}\text { Learning disabilities in children } \\
\text { Yes } \\
\text { NO }\end{array}$ & $\begin{array}{l}13 \\
60\end{array}$ & $\begin{array}{l}17.8 \% \\
82.2 \%\end{array}$ \\
\hline
\end{tabular}


Regarding the acute toxic effects of CDs, Table (1) showed that more than half of the study group frequently complained of recurrent headache $(64.4 \%)$, skin irritation (63\%) in the form of itching or redness, eye irritation $(61.6 \%)$, and nearly half of the nurses complained of hair loss. As regard GIT symptoms, nurses complained of metallic taste (32.9\%), and nausea or vomiting (41.1\%). Regarding reproductive health effects: almost one third (32.9\%) of nurses complained of menstrual irregularities, while (23.3\%) had low birth weight babies, (19.2\%) suffered from premature labor and $17.8 \%$ of nurses suffered from abortions, infertility or subfertility and having children with learning disabilities .

Table (2): Safety measures applied during handling CDs by the study group and barriers to compliance with NIOSH guidelines.

\begin{tabular}{|l|c|c|}
\hline Safety precautions & No & $\%$ \\
\hline Utilization ${ }^{\#}$ of PPE when handling CDS & 65 & $89.0 \%$ \\
Gloves & 0 & $0.0 \%$ \\
Goggles & 45 & $61.6 \%$ \\
Gowns & 45 & $61.6 \%$ \\
Masks & & \\
\hline Washing hands after removing gloves & 5 & $6.8 \%$ \\
Yes & 68 & $93.2 \%$ \\
NO & & \\
\hline Utilization ${ }^{\#}$ PPE during spills & 42 & $57.5 \%$ \\
Masks & 0 & $0.0 \%$ \\
Goggles & 36 & $49.3 \%$ \\
Gowns & 51 & $69.9 \%$ \\
Gloves & 57 & $78.1 \%$ \\
\hline Using spill kits during spills & & \\
Yes & & \\
NO & & \\
\hline
\end{tabular}




\begin{tabular}{|l|c|c|}
\hline Barriers to compliance with NOISH guidelines & No & $\%$ \\
\hline Work overload & 30 & $41.1 \%$ \\
\hline Lack of supervision & 9 & $12.3 \%$ \\
\hline Don't know that there are guidelines & 6 & $5.5 \%$ \\
\hline PPE is uncomfortable to wear & 24 & $8.2 \%$ \\
\hline PPE is not always available & & $32.9 \%$ \\
\hline
\end{tabular}

(\#) More than one personal protective equipment could be used PPEs: Personal protective equipments CDs: Cytotoxic drugs NOISH: National Institute for Occupational Safety and Health

Table (2) illustrated that the majority of nurses (89\%) utilized gloves, $(61.6 \%)$ utilized gowns, $(61.6 \%)$ utilized masks and none of them utilized goggles during handling of CDs. Almost all of the participants who used gloves (93.2\%) did not wash their hands after removing gloves. As regard utilization of PPE during spills, (69.9\%) of nurses utilized gloves, none of them utilized goggles and only few of them $(21.9 \%)$ used spill kits during spills. Regarding barriers to compliance with the NIOSH guidelines, it was obvious that work overload was the most important barrier as reported by (41.1\%) of nurses, followed by unavailability of PPE (32.9\%), and lack of supervision by head nurse (12.3\%). Uncomfortable PPE and ignorance of the presence of guidelines were the least important barriers to compliance as reported only by $(8.2 \%)$ and $(5.5 \%)$ of nurses, respectively.

\section{Table (3): Knowledge assessment score and frequency of training courses received $(\mathrm{No}=73)$}

\begin{tabular}{|l|c|c|}
\hline Total knowledge assessment score & No & $\%$ \\
\hline Good & 8 & $11.0 \%$ \\
\hline Fair & 53 & $72.6 \%$ \\
\hline
\end{tabular}




\begin{tabular}{|c|c|c|}
\hline Bad & 12 & $16.4 \%$ \\
\hline Training courses received & No & $\%$ \\
\hline \multicolumn{3}{|l|}{ Receiving training courses on handling CDs } \\
\hline Yes & 42 & $57.5 \%$ \\
\hline NO & 31 & $42.5 \%$ \\
\hline \multicolumn{3}{|l|}{ If yes, these courses were: } \\
\hline On regular basis & 10 & $23.8 \%$ \\
\hline Once and insufficient & 32 & $76.2 \%$ \\
\hline \multicolumn{3}{|l|}{ If yes, courses provided with illustrated materials } \\
\hline Yes & 30 & $71.4 \%$ \\
\hline NO & 12 & $28.6 \%$ \\
\hline \multicolumn{3}{|l|}{ Source of information about CDs } \\
\hline Hospital administration & 60 & $82.2 \%$ \\
\hline Mass media & 2 & $2.7 \%$ \\
\hline Others (university, textbook, internet) & 11 & $15.1 \%$ \\
\hline \multicolumn{3}{|l|}{ Nurses desire more educational courses } \\
\hline Yes & 69 & $94.5 \%$ \\
\hline NO & 4 & $5.5 \%$ \\
\hline
\end{tabular}

Table 3 showed that the majority (72.6\%) had fair total knowledge score. As regards training courses about CDs handling safety measures: almost half (57.5\%) of nurses received training courses about safe handling of cytotoxic drugs; however, the majority $(76.2 \%)$ reported that they received these courses only once. Training was provided with illustrated material in $(71.4 \%)$ of these courses. Moreover, the majority $(82.2 \%)$ of nurses had their source of information about CDs from hospital administration; while $15.1 \%$ had their source of information from text books, university and internet, and only $2.7 \%$ from mass media. The majority of participants $(94.5 \%)$ had desire for more safety education on practical work. 
Table (4): Relation between knowledge score and risky behaviors at work areas.

\begin{tabular}{|c|c|c|c|c|c|c|}
\hline \multirow[b]{2}{*}{ Risky behaviors } & \multicolumn{3}{|c|}{ Knowledge level } & \multirow[b]{2}{*}{$\begin{array}{l}\text { Total } \\
\text { No\% }\end{array}$} & \multirow{2}{*}{$\begin{array}{c}\text { Fisher } \\
\text { exact } \\
\text { test }\end{array}$} & \multirow{2}{*}{$\begin{array}{c}\mathbf{p} \\
\text { value }\end{array}$} \\
\hline & $\begin{array}{c}\text { Poor } \\
\text { No } \%\end{array}$ & $\begin{array}{c}\text { Fair } \\
\text { No } \%\end{array}$ & $\begin{array}{c}\text { Good } \\
\text { No } \%\end{array}$ & & & \\
\hline $\begin{array}{l}\text { Eating food } \\
\text { Yes } \\
\text { NO }\end{array}$ & $\begin{array}{ll}5 & (22.7) \\
7 & (13.7)^{-}\end{array}$ & $\begin{array}{ll}17 & (77.3) \\
36 & (70.6)\end{array}$ & $\begin{array}{c}0 \\
8(15.7)\end{array}$ & $\begin{array}{l}22(100.0) \\
51(100.0)\end{array}$ & 2.02 & 0.34 \\
\hline $\begin{array}{l}\text { Drinking beverage } \\
\text { Yes } \\
\text { NO }\end{array}$ & $\begin{array}{ll}7 & (24.1)^{-} \\
5 & (11.4)^{-}\end{array}$ & $\begin{array}{l}21(72.4) \\
32(72.7)\end{array}$ & $\begin{array}{ll}1 & (3.5) \\
7 & (15.9)\end{array}$ & $\begin{array}{l}29(100.0) \\
44(100.0)\end{array}$ & 0.24 & 1.00 \\
\hline $\begin{array}{l}\text { Storing food and beverage } \\
\text { Yes } \\
\text { NO }\end{array}$ & $\begin{array}{c}7(33 . .3) \\
5(9.6)\end{array}$ & $\begin{array}{l}14(66.7) \\
39(75.0)\end{array}$ & $\begin{array}{c}0 \\
8(15.4)\end{array}$ & $\begin{array}{l}21(100.0) \\
52(100.0)\end{array}$ & 1.1 & 0.67 \\
\hline $\begin{array}{l}\text { Priming IV tube at patient } \\
\text { bed } \\
\text { Yes } \\
\text { NO }\end{array}$ & $\begin{array}{l}6(15.0) \\
6(18.2)\end{array}$ & $\begin{array}{l}28(70.0) \\
25(75.7)\end{array}$ & $\begin{array}{l}6(15.0) \\
2(6.1)\end{array}$ & $\begin{array}{l}40(100.0) \\
33(100.0)\end{array}$ & 0.76 & 0.79 \\
\hline $\begin{array}{l}\text { Taking contaminated clothes } \\
\text { home } \\
\text { Yes } \\
\text { NO }\end{array}$ & $\begin{array}{ll}8 & (21.6) \\
4 & (11.1)\end{array}$ & $\begin{array}{ll}25 & (67.6) \\
28 & (77.8)\end{array}$ & $\begin{array}{l}4(10.8) \\
4(11.1)\end{array}$ & $\begin{array}{l}37(100.0) \\
36(100.0)\end{array}$ & 1.93 & 0.42 \\
\hline $\begin{array}{l}\text { Spill or leak of the CDs drug } \\
\text { Yes } \\
\text { NO }\end{array}$ & $\begin{array}{c}10(23.8) \\
2(6.5)\end{array}$ & $\begin{array}{l}28(66.7) \\
25(80.6)\end{array}$ & $\begin{array}{l}4(9.5) \\
4(12.9)\end{array}$ & $\begin{array}{l}42(100.0) \\
31(100.0)\end{array}$ & 2.13 & 0.33 \\
\hline
\end{tabular}

(\#) percentages were taken from the row.

Table (4) revealed no statistically significant difference between total knowledge scores and risky behaviors among the study group such as eating or drinking beverages during handling CDs, priming intravenous line at patient bed-side and taking contaminated clothes home $(p>0.05)$. However it is to be noted that for each risky behavior, the percentage of nurses from the fair knowledge score group is more than twice that from the poor knowledge score group. 
Table (5): Assessment of safety measures at the Oncology unit by nurses (No=73).

\begin{tabular}{|c|c|c|}
\hline Items & $\mathrm{No}=73$ & $\%$ \\
\hline $\begin{array}{l}\text { There are enough PPE in the unit } \\
\text { Yes } \\
\text { NO }\end{array}$ & $\begin{array}{l}16 \\
57\end{array}$ & $\begin{array}{l}21.9 \\
78.1\end{array}$ \\
\hline $\begin{array}{l}\text { Head nurse always corrects wrong practice } \\
\text { Yes } \\
\text { NO }\end{array}$ & $\begin{array}{l}56 \\
17\end{array}$ & $\begin{array}{l}76.7 \\
23.3\end{array}$ \\
\hline $\begin{array}{l}\text { The unit is not crowded } \\
\text { Yes } \\
\text { NO }\end{array}$ & $\begin{array}{l}45 \\
28\end{array}$ & $\begin{array}{l}72.6 \\
38.4\end{array}$ \\
\hline $\begin{array}{l}\text { The unit is clean } \\
\text { Yes } \\
\text { NO }\end{array}$ & $\begin{array}{c}65 \\
8\end{array}$ & $\begin{array}{l}89.0 \\
11.0\end{array}$ \\
\hline $\begin{array}{l}\text { Policy prevents pregnant women from work in unit } \\
\text { Yes } \\
\text { NO }\end{array}$ & $\begin{array}{l}27 \\
46\end{array}$ & $\begin{array}{l}37.0 \\
63.0\end{array}$ \\
\hline $\begin{array}{l}\text { Medical surveillance program for employees } \\
\text { Yes } \\
\text { NO }\end{array}$ & $\begin{array}{l}27 \\
46\end{array}$ & $\begin{array}{l}37.0 \\
63.0\end{array}$ \\
\hline $\begin{array}{l}\text { Reporting system for any health hazards related to } \\
\text { handling } \\
\text { Yes } \\
\text { NO }\end{array}$ & $\begin{array}{l}31 \\
42\end{array}$ & $\begin{array}{l}42.5 \\
57.5\end{array}$ \\
\hline $\begin{array}{l}\text { Policies and procedure as regards CDs handling } \\
\text { Yes } \\
\text { NO }\end{array}$ & $\begin{array}{c}43 \\
30\end{array}$ & $\begin{array}{l}58.9 \\
41.1\end{array}$ \\
\hline $\begin{array}{l}\text { Presence of laminar airflow hood in work area } \\
\text { Yes } \\
\text { NO }\end{array}$ & $\begin{array}{r}0 \\
73\end{array}$ & $\begin{array}{c}0.00 \\
100\end{array}$ \\
\hline
\end{tabular}

PPE: Personal protective equipment CDs: Cytotoxic drugs

Assessment of the working environment by nurses was illustrated in Table (5). The majority of nurses reported that their working unit was clean $(89 \%)$, not crowded (72.6\%) and that the head nurse always supervises them and corrects their wrong practices $(76.7 \%)$. Almost more than half $(58.9 \%)$ of nurses reported that there were policies and procedures in the unit to decrease hazardous exposure to CDs. On 
the other hand, only few (21.9\%) reported that PPE were adequate in the unit, only $(37.0 \%)$ of nurses reported that there was a clear policy to restrict pregnant women from handling CDs and that there was a regular medical surveillance program for them. Reporting system for any health hazards related to handling CDs was only reported by (42.5\%) of participants. All nurses reported that there was no laminar air flow hood in their working unit.

\section{Discussion}

The findings of the current study indicate a high frequency of several health hazards among nurses exposed to CDs; as regards acute toxic effects, more than half of the nurses frequently complained of recurrent headache (64.4\%), skin irritation (63\%), eye irritation (61.6\%), and upper air way irritation (50.7\%) (Table1). These symptoms may be related to work as the majority of nurses $(70.5 \%)$ reported that they improved on vacations. Eye irritation could be attributed to the fact that none of the studied nurses wear protective goggles during preparation of the drug (Table 2). While the majority (89\%) wears gloves during handling the drug, yet (63\%) suffered from skin irritation (Table 1) which showed that single layer gloves are not protective as two layers of disposable gloves as recommended by NIOSH guidelines (2004). The above results are in line with an Asian study done by Turk et al., (2004) on knowledge, attitude and safe behavior of nurses handling cytotoxic anticancer drugs who stated that recurrent headache was the most pronounced symptom among nurses handling CDs in the Oncology unit followed by eye and respiratory irritation.

As regards the reproductive effects of CDs, the current study revealed that almost one third $(32.9 \%)$ of nurses complained of menstrual irregularities; while (23.3\%) had low birth weight babies, (19.2\%) suffered from premature labor and they suffered from abortions, infertility and having children with learning difficulties (18\%) each (Table1). Several studies have associated occupational exposure to CDs with adverse reproductive outcomes including, spontaneous abortions, infertility and congenital anomalies (Pethran et al., 2003 and NIOSH, 2007). A study from China on the effects of occupational exposure 
of female nurses to antineoplastic drugs on pregnancy outcome and embryonic development ; they reported significant increase in premature birth, spontaneous abortion, and congenital malformations in nursing personnel handling chemotherapeutic drugs (Zhao et al., 1996). Another study done by Martin (2005) on chemotherapy handling and its effects among nurses and their offspring; they detected learning disabilities among children of nurses who had handled CDs during their work.

In the current study, (89\%) of nurses used gloves when handling CDs, however only $(61.6 \%)$ utilized gowns, $(61.6 \%)$ used masks and none of them utilized goggles. As regard utilization of personal protective equipment during spills, only (69.9\%) of nurses utilized gloves (Table 2).The results of our work were consistent with that obtained by Al-Ghamdi and Al-Mustafa (1997) who reported that the majority of nurses handling CDs had integrated gloves use into their practice. The present study noted an increase in the usage of gloves and masks as compared to the study which was conducted in El-Mansoura by (Elshamy et al., 2010). The use of goggles was limited in both studies.
As regard the score of knowledge assessment, the majority of the studied nurses $(72.6 \%)$ had fair knowledge score; and only $(11.0 \%)$ had good total score (Table 3). The lack of knowledge particularly on "methods of exposure" and "preventive measures" is of concern, because it increases the health workers' unsafe behaviors. The above results were similar to a previous study conducted by Mohsen and Fareed, (2013) who revealed that the majority of their study nurses handling CDs (77.8\%) had fair knowledge score. This is in contrast to what detected by Mohesen et al., (2011), who reported that almost $75 \%$ of respondents lack any essential knowledge as regards CDs safety procedures.

Participating in training courses with stress on the importance of protective measures is highly recommended; the level of knowledge will significantly improve and safety practice will be more likely to adopt as reported by Mohsen and Fareed, (2013) who found significant progress in nurses' knowledge and safety practice regarding CDs handling after applying educational intervention programs.

The present study showed that almost all of those with good knowledge 
scores did not drink or eat or store food or beverages at the work area; however the relations were not statistically significant (Table 4). The nonsignificant results might be due to the small sample size used. This is similar to a study conducted by Ramanand and Basant, (2012) in Nepal which found the same non-significant results.

With respect to receiving previous training, the current study showed that ( $57.5 \%$ ) of studied nurses received training courses about safe handling of CDs; however, the majority (76.2\%) reported that these courses were given once and were insufficient and almost all the participants showed their intense desire to have such courses on regular basis (Table 3). The result of this study is in agreement to that of Rizalar et al., (2012) who stated that about half of their study nurses had undergone specialized training for handling and administrating CDs; however, in contrast to this study, a previous Egyptian study reported that only few nurses had attended such programs (Mohsen and Fareed, 2013).

Concerning barriers against following the safety precautions, it was noticed from the current study that $(41.1 \%)$ of the study nurses mentioned that heavy work load was the main barrier against following the safety precautions (Table 2). This is consistent with the result of Fareed and Dorgham, (2010) on their work on hand hygiene among Egyptian health care students and declared that half of their study group stated that high work load was the major factor interfering with their compliance with safe practice measures.

Regarding chemotherapy unit assessment, the present study showed that personal protective equipment were not adequate in the unit as reported by (78.1\%) of nurses (Table5); this was not in accordance with Mohsen and Fareed, (2013) study who mentioned that personal protective equipment in their study setting were highly available.

The current work revealed that regular checkup was done only for $(37.0 \%)$ of the participants (Table 5); this agreed with Turk et al., (2004) who mentioned that a minority of the studied nurses had periodic health examination. It was striking to find that more than half of the studied nurses (63.\%) reported that there was no strict policy to prevent pregnant women from working in the unit, this goes in line with Elshamy et al., (2010) who found the same result. Also the nurses reported that their working environment had no laminar air flow 
hood; they stated that there is one safety cabinet in the whole Oncology center to prepare CDs drugs for outpatients and nurses in the ward are only allowed to prepare the CDs in the safety cabinet if the nurses in outpatient clinics finished their drug's preparation. So many times; they just prepare the drug outside the safety cabinet. This finding showed that the working place was not a safe environment. Similar results have been reported in previous studies (Sessink, 1992; Ramanand and Basant, 2012). However, in some studies, especially in the most developed countries, the majority of nurses prepared CDs in a laminar air flow hood (Verplank et al., 2007; and Kim et al., 2011).

\section{Conclusion and recommendations}

The present study concluded that toxic effects of CDs were highly prevalent among the studied group. While the majority of nurses had fair knowledge score regarding safe handling of CDs, their practice and adopting protective measures were not satisfactory.

The safety committee of the hospital should ensure the appropriate implementation of safety policies especially that prevents pregnant nurses from handling CDS. This study also revealed the necessity of improvement of the work environment and the need to provide adequate personal protective devices and specialized equipment such as air laminar flow hoods and aspiration systems to protect the health of our workers from hazardous effects of cytotoxic drugs.

Limitations of the study: The number of nurses who were specialized in handling chemotherapeutic drugs was very small so that the study does not allow for generalization of the study results.

\section{Conflict of interest}

There was no conflict of interest.

\section{References}

1. Al-Azzam BT, Awawdeh KH and Alkafajei M (2015): Compliance with safe handling guidelines of antineoplastic drugs in jordanian hospitals. J Oncol Pharm Pract; 21(1): 3-9.

2. Al-Ghamdi MS and Al-Mustafa ZH (1997): The Handling of Anticancer Drugs in Riyadh and the Eastern Province. Annals of Saudi Medicine; 17(2):257-9.

3. Anwar WA, Salama SI, el Serafy MM, Hemida SA and Hafez AS (1994) : Chromosomal aberrations and micronucleus frequency in nurses occupationally exposed to cytotoxic drugs .Mutagenesis;9 (4 ):315-7

4. Connor TH and Mcdiarmid MA (2006): Preventing occupational exposures to antineoplastic drugs in health care settings.CA Cancer J Clin; 56(6):354-65.

5. Elshamy K, El-Hadidi M, El-Roby and Fouad M (2010): Health hazards among oncology 
nurses exposed to chemotherapy drugs. Afr $\mathbf{J}$ Haemat Oncolog; (1) 3: 70-8.

6. Fareed M and Dorgham L (2010): Hand hygiene among Egyptian health care students: Nursing versus Medical students. Egyp J Med;43 (4): 58-69

7. Kim K, Lee HS, Kim MH and Choi S (2011): Guideline adherence to chemotherapy administration safety standards: A survey on nurses in a single institute. J Gynecol Oncol;22:49-52

8. Krstev S, Peruničić B and Vidakovic A (2003): Work practice and some adverse health effects in nurses handling antineoplastic drugs. Med Lav; 94(5):432-9.

9. Martin S (2005): Chemotherapy handling and effects among nurses and their offspring (abstract) .Oncology Nursing Forum; 32:425

10. Mohamed NA (2015): Effect of Designed Nursing Protocol on Nurse's Knowledge and Practice Regarding Chemotherapy. Med J Cairo Univ; 83: 2

11. Mohsen M, Fareed M, El-shikh A and Abbas S (2011): Effect of nursing management protocol on selected side effects of chemotherapy drugs. J Am sci ; 7 (6):54

12. Mohsen M and Fareed M (2013): Chemotherapy Safety Protocol for Oncology Nurses: World Academy of Science. International Journal of Medical and Health Sciences; 7 (9).

13. National Institute for Occupational Safety and Health (NIOSH) (2004): Preventing Occupational Exposures to Antineoplastics and Other Hazardous Drug in Health Care Settings. Retrieved from http://www.cdc.gov/niosh/ docs/2004-165/pdfs/2004- 165.

14. National Institute for Occupational Safety and Health (NIOSH) (2007): NIOSH Publication No. 2007-117: Medical Surveillance for Health Care Workers Exposed to Hazardous Drugs

15. National Institute for Occupational Safety and Health (NIOSH) (2013): NIOSH List of
Antineoplastic and Other Hazardous Drugs in Health Care Settings. Available at; http://www. cdc.gov/niosh/docs/2010-167

16. Occupational Safety and Health Administration (OSHA) (2016): Controlling occupational exposure to hazardous drugs. OSHA Safety and Health Topics: Hazardous Drugs

17. Pethran A, Schierl R, Hauff K, Grimm CH, Boos KS, et al. (2003): Uptake of antineoplastic agents in pharmacy and hospital personnel. Part 1: monitoring of urinary concentrations. Int Arch Occup Environ Health; 76:5-10.

18. Ramanand C and Basant K (2012): Chemotherapy-Knowledge and Handling Practice of Nurses Working in a Medical University of Nepal. B. P. Koirala Institute of Health Sciences. Nepal journal of Cancer Therapy;3:110- 14

19. Rizalar S, Tural E and Altay B (2012): Nurses' protective measures during chemotherapy preparation and administration in Turkey. Int $\mathbf{J}$ Nurs Pract; 18(1): 1-16

20. Sessink PJ, Boer KA, Scheefhals AP, Anzionand RB and Bos RP (1992): Occupational Exposure to Antineoplastic Agents at Several Departments in a Hospital. Int Arch Occ Env Hea; 6:105-12.

21. Turk M, Davas A and Mercan T (2004): Knowledge, attitude and safe behavior of nurses handling cytotoxic anticancer drugs. Asian Pac J Cancer P; 5 (1):164-8.

22. Verplank AJ, Herber RF and Bos RP (2007): Occupational Exposure to Antineoplastic Agents and Parameters for Renal Dysfunction. Int Arch Occ Env Hea; 69 (3): 215-218.

23. World Health Organization (2006): Fact sheet No.297. WHO Media Centre Fact Sheet

24. Zhao SF, Zhang XC, Wang QF and Bao YS (1996): The effects of occupational exposure of female nurses to antineoplastic drugs on pregnancy outcome and embryonic development. Teratology; 53:94. 
